\title{
Targeted expression of a toxin gene to adipose tissue: transgenic mice resistant to obesity
}

\author{
Susan R. Ross, ${ }^{1,4}$ Reed A. Graves, ${ }^{2,3}$ and Bruce M. Spiegelman ${ }^{2}$ \\ ${ }^{1}$ Department of Biochemistry (m/c 536), University of Illinois College of Medicine, Chicago, Illinois 60612 USA; \\ ${ }^{2}$ Dana-Farber Cancer Institute and the Department of Biological Chemistry and Molecular Pharmacology, Harvard Medical \\ School, Boston, Massachusetts 02115 USA
}

\begin{abstract}
Obesity is characterized by increased adipose tissue mass and is often accompanied by a number of other disorders, such as diabetes, hypertension, and hyperlipidemia. To investigate the interrelationship between excessive adipose tissue mass and these associated disorders, we have attempted to reduce adiposity via targeted expression of an attenuated diphtheria toxin A chain to adipose tissue, using the $5^{\prime}$ regulatory region of the adipocyte P2 (aP2) gene. Transgenic mice with high levels of toxin expression developed chylous ascites and died shortly after birth. Transgenic mice expressing lower levels of the transgene had normal adiposity and survived to adulthood; however, they showed a complete resistance to chemically induced obesity. Nevertheless, these animals developed hyperlipidemia equal to or greater than their nontransgenic obese littermates. Moreover, MSG-treated transgenic females were fertile, unlike their obese nontransgenic littermates. These data demonstrate the feasibility of genetic manipulation of adiposity and allow a functional dissection of obesity and its metabolic sequelae.
\end{abstract}

[Key Words: Adipose tissue; transgenic mice; obesity; toxin gene]

Received April 6, 1993; revised version accepted April 29, 1993.

Obesity refers to a complex and heterogeneous group of disorders in which there is an excess of adipose tissue. This increase leads to a perturbation in the general metabolic state, and as a result, obesity is a major risk factor for a number of clinical diseases, such as non-insulindependent diabetes mellitus (NIDDM), cardiovascular disease, hyperlipidemia, and hypertension. Because of these associated diseases, the life expectancy of the obese individual is greatly decreased (Foster 1985). A key question in obesity research is the nature of the mechanistic link between increased adiposity and the clinical disorders that accompany it.

There are several animal models in which obesity has been shown to be inherited as a genetic trait, but neither the gene defect nor its mechanism of action is known (Coleman 1982; Leiter et al. 1987; Friedman and Leibel 1992). Because physical or chemical lesions of the hypothalamus [such as neonatal administration of monosodium glutamate (MSG) (Olney 1969)| induce obesity, it is thought that some genetic forms of this syndrome result from aberrant signaling from this tissue. (Bray and York 1979).

The hypothalamus secretes hormones involved in

${ }^{3}$ Present address: Gastroenterology Section, Department of Medicine, University of Chicago, Chicago, Illinois 60637 USA.

${ }^{4}$ Corresponding author. many different biological functions, including releasing factors necessary to stimulate secretion of pituitary, adrenal, and thyroid hormones. In obese animals, the levels of many of these hormones are altered, although it is not known whether this is a direct effect of the mutation or the result of a general perturbation of the physiological state of these animals (Bray and York 1979). It is therefore likely that the hypothalamic defect that results in increased adipose tissue also affects other pathways.

The animal obesity models demonstrate that obesity results in pleiotropic systemic defects. In addition to the correlates described above, many obese animals exhibit, for example, decreased fertility, which is thought to be attributable to both to physical constraints and to inappropriate gonadotropin secretion stemming from hypothalamic dysfunction (Bray and York 1979). Specifically, female, but not male, mice induced to become obese after neonatal treatment with MSG have been shown to be infertile (Olney 1969). In addition, MSG-treated mice of both sexes have shortened body axes, a feature thought to be attributable to reduced pituitary function also resulting from hypothalamic damage (Olney 1969).

To determine which of these effects is the direct result of excess adipose tissue or the systemic defect that results in obesity, we created transgenic mice in which an attenuated diphtheria toxin A (DT-A) chain gene (Breitman et al. 1990) was expressed specifically in adipose 
cells. High-level DT-A expression was lethal in newborn mice, which developed chylous ascites. Transgenic mice that expressed low levels of the toxin gene were relatively normal; however, they were completely resistant to MSG-induced obesity. Moreover, although they lacked the massive adipose stores characteristic of obesity, they still developed the clinical correlates of hyperlipidemia and fatty liver. Finally, reduction of the adipose stores in MSG-treated transgenic females restored fertility. These results show that transgenic mice will provide useful models for the dissection of obesity and its clinical correlates.

\section{Results}

High levels of transgene expression cause neonatal lethality

To target expression of the DT-A gene to adipose tissue, we used the regulatory region from the adipocyte-specific adipocyte $\mathrm{P} 2$ (aP2) gene; our previous work showed that this $5.4-\mathrm{kb}$ fragment targets expression of linked genes specifically to adipose tissue (Ross et al. 1990, 1992; Graves et al. 1991). Similar experiments in transgenic animals using other tissue-specific regulatory regions have shown that targeted ablation of a specific cell type in the context of the whole animal can be a powerful tool for the study of organ development and function (Palmiter et al. 1987; Behringer et al. 1988; Bernstein and Breitman 1989; Evans 1989; Breitman et al. 1990; Kendall et al. 1991). The DT-A protein inactivates eukaryotic elongation factor-2, resulting in the inhibition of protein synthesis and cell death. We chose to use an attenuated form of the DT-A gene (tox-176) because it has been reported to be $\sim 15-$ to 30 -fold less potent than the wild-type DT-A gene (Maxwell et al. 1987; Breitman et al. 1990) and must be produced at high levels to kill cells in which it is expressed. Therefore, cells expressing low levels of the gene are able to survive, although their function is affected (Breitman et al. 1990). Moreover, because the level of transgene expression varies from strain to strain as a result of copy number and position effects, we expected that the use of the attenuated DT-A gene would result in animals with a range of phenotypes depending on the amount of toxin protein produced in adipose tissue.

Nine founder animals that contained the DT-A expression vector were generated in the SW outbred background. Two of the founders expired within 1 day after birth, and this neonatal lethality was accompanied by the presence of a milky fluid in the peritoneal cavity, termed chylous ascites. The chylous ascites phenotype was originally described as a semidominant, incompletely penetrant nonlethal mutation affected by the ragged $\{R a)$ gene (Herbertson and Wallace 1964; Wallace 1979) and was characterized by the presence of a milky white fluid composed of chylomicrons and lipid globules in the peritoneal cavity of newborn mice.

The seven viable founders were mated with nontransgenic mice to generate pedigrees, and the chylous/as- cites phenotype was also observed in the G1 offspring of three of the founders, strains 2,6 , and 18 (Table 1). These three founder animals transmitted the transgene to only $3.5 \%-15 \%$ of their offspring. All three strains had approximately normal litter sizes (i.e., 8-12 pups per litter), and this phenotype was not observed in $>300$ nontransgenic mice born from these crosses. DNAs isolated from the tissues of strain 2, 6, and 18 mice and their offspring were compared by Southern blot analysis for the transgene sequences, and indicated that all three founder animals were somatic mosaics (data not shown). Thus, it is likely that the white adipose tissue of these founders was composed of nontransgenic fat cells that provided normal fat cell function, whereas the Gl transgenic offspring that inherited a copy of the transgene in every fat cell were unable to survive because of loss of adipocyte function.

Newborn transgenic pups of strains 2, 6, and 18 expressed very high levels of the DT-A transgene specifically in adipose tissue, as shown in Figure 1, where the results of Northern blot and RNase $T_{1}$ protection analyses of RNA isolated from the interscapular brown adipose tissue (BAT) from 15 transgenic pups is shown [newborn rodents lack detectable WAT (Ailhaud et al. 1992); therefore, we tested expression in BAT]. Expression of the DT-A transgene was detected in BAT of the transgenic neonates and not in the liver or brain (data not shown). We also hybridized these Northern blots with a cDNA probe for the aP2-coding region and for the BATspecific uncoupling protein (UCP) gene and found that both of these were detectable, although reduced in comparison with their nontransgenic littermates (Fig. 1A). The chylous ascites phenotype was not studied further.

\section{Viable DT-A transgenic mice are resistant to obesity}

These results suggested that functional adipose tissue

Table 1. Phenotype of viable aP2-DT-A transgenic mice

\begin{tabular}{ccccc}
\hline & & & & $\begin{array}{l}\text { Newborn } \\
\text { lethality } \\
\text { (chylous }\end{array}$ \\
Strain & Sex & Transmission $^{\text {a }}$ & Expression $^{\text {b }}$ & \begin{tabular}{l} 
ascites) \\
\hline 1
\end{tabular} F $^{\text {and }}$ \\
2 & F & $11 / 52(40 \%)$ & + & no \\
6 & F & $10 / 57(15 \%)$ & ++++ & yes \\
8 & F & $21 / 63(33 \%)$ & ++ & yes \\
12 & F & $5 / 40(13 \%)$ & - & no \\
13 & F & $14 / 28(50 \%)$ & - & no \\
18 & F & $3 / 85(3.5 \%)$ & +++ & no \\
\hline
\end{tabular}

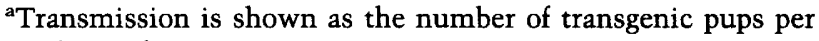
total pups born.

bexpression was analyzed by Northern blot and RNase protection assays of RNA isolated from the BAT of newborns (strains 2 and 6) and the BAT and WAT of adults (strains 1, 8, 12, and 13). Relative levels of expression were estimated by comparison of the hybridization signal obtained in these analyses, with the highest expressing animals represented by ++++ and nonexpressing animals by - .

${ }^{c}$ Newborn lethality and chylous ascites phenotype were seen in transgenic offspring in the G2 generation. 


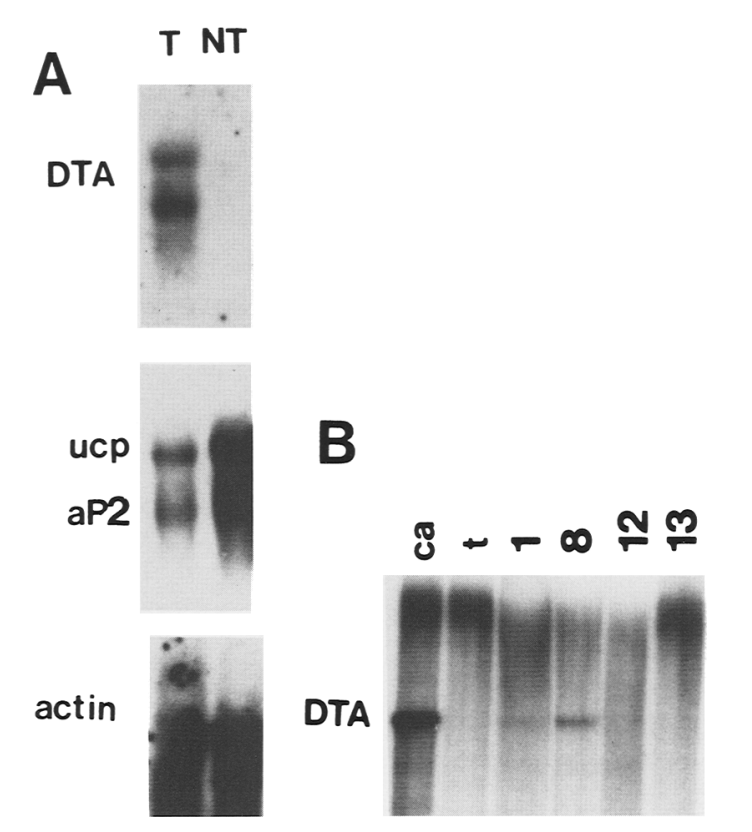

Figure 1. Expression analysis of aP2-DT-A transgenic mice. (A) Northern blot analysis of RNA isolated from the BAT of chylous ascites-containing newborn transgenic pups. Transgenic animals were identified by PCR analysis of tail DNA. Twenty micrograms of total RNA isolated from 15 pooled newborn transgenic strain 6 pups $(T)$ or their nontransgenic littermates (NT) was subjected to Northern blot analysis. The blot was hybridized first with a diphtheria toxin probe (DT-A) and then stripped and hybridized with probes for the mitochondrial uncoupling protein $(\mathrm{UCP})$ and endogenous aP2-coding region genes, and then with a probe for the mouse $\beta$-actin gene. $(B)$ RNase protection analysis of RNA isolated from the WAT of adult 5.4aP2-DT-A transgenic mice. One hundred micrograms of total RNA isolated from the epididymal WAT of strains 1,8 , 12 , and 13 was subjected to RNase $T_{1}$ protection analysis, using a probe that detects the $3^{\prime}$ SV40 polyadenylation signals present in the diphtheria toxin transgene. As controls, $5 \mu \mathrm{g}$ of the newborn BAT RNA (ca) and yeast tRNA ( $t$ ) was also subjected to this analysis.

was required for normal postnatal development. The remaining four transgenic animals either did not express the transgene in any tissue (Fig. 1B, strains 12 and 13) or expressed the transgene specifically in adipose tissue at $\sim 100$-fold lower levels than that seen in the BAT of the neonatal lethal strains [compare the signal from $100 \mu \mathrm{g}$ of total RNA from strains 1 and 8 with that from $5 \mu \mathrm{g}$ of RNA from the neonatal BAT lethal strain (ca) in Fig. 1B]. In strains with a low level of DT-A expression (1 and 8), the adipose tissue appeared relatively normal and the WAT weights were in the normal range (Table 2).

Although strains 1 and 8 appeared phenotypically normal, we tested whether it was possible to induce obesity in these strains. To generate obesity, MSG was injected into newborn rodents of both strains derived from a cross between heterozygous transgenic and nontransgenic animals; therefore, $\sim 50 \%$ of each litter inherited the transgene, and their nontransgenic littermates served as con-
Table 2. MSG-injected transgenic mice are resistant to obesity and develop hepatomegaly

\begin{tabular}{lccll}
\hline & & \multicolumn{3}{c}{ Weight (grams) } \\
\cline { 3 - 5 } Strain & MSG & total body & WAT $^{\mathrm{a}}$ & liver \\
\hline 1 & no & $35 \pm 2.5$ & $0.74 \pm 0.14$ & $1.6 \pm 0.08$ \\
& & $(33-38)$ & $(0.61-0.89)$ & $(1.5-1.7)$ \\
8 & no & $28.8 \pm 3.9$ & $0.35 \pm 0.06$ & $1.5 \pm 0.52$ \\
& & $(26-31.5)$ & $(0.31-0.4)$ & $(1.2-2.1)$ \\
$\mathrm{NT}^{\mathrm{b}}$ & no & $30.4 \pm 2.1$ & $0.44 \pm 0.1$ & $1.5 \pm 0.05$ \\
& & $(28-31.9)$ & $(0.35-0.54)$ & $(1.4-1.5)$ \\
1 & yes & $28.5 \pm 1.1$ & $0.21 \pm 0.05$ & $4.0 \pm 1.1$ \\
& & $(27.3-29.5)$ & $(0.17-0.26)$ & $(2.8-4.8)$ \\
8 & yes & 28.3 & $<0.1$ & 3.2 \\
$\mathrm{NT}^{\mathrm{b}}$ & yes & $41.5 \pm 1.4$ & $2.2 \pm 0.5$ & $1.9 \pm 0.25$ \\
& & $(39.9-43)$ & $(1.47-2.7)$ & $(1.7-2.2)$ \\
\hline
\end{tabular}

The numbers represent the average of two to four males $\sim 3-5$ months of age, except for strain $8(+M S G)$, which is one animal; numbers in parentheses show the range. MSG-injected strain 1 and nontransgenic animals are littermates.

a(WAT) Epididymal fat pad weight.

b(NT) Nontransgenic.

trols. MSG treatment of neonatal mice induces a hypothalamic lesion that results in the development of marked obesity beginning at the age of 6-10 weeks (Olney 1969; Pizzi and Barnhart 1976). For the first month after birth, the weights of the nontransgenic and transgenic littermates were indistinguishable. At $\sim 6$ weeks of age, the average total body weight of the non-transgenic mice began to surpass that of their transgenic littermates (Fig. 2), and it became visually obvious that the transgenic mice were not developing the large subcutaneous WAT pads characteristic of this model of obesity (Fig. $3 \mathrm{~A}, \mathrm{~B})$. By $4-5$ months of age, the nontransgenic animals

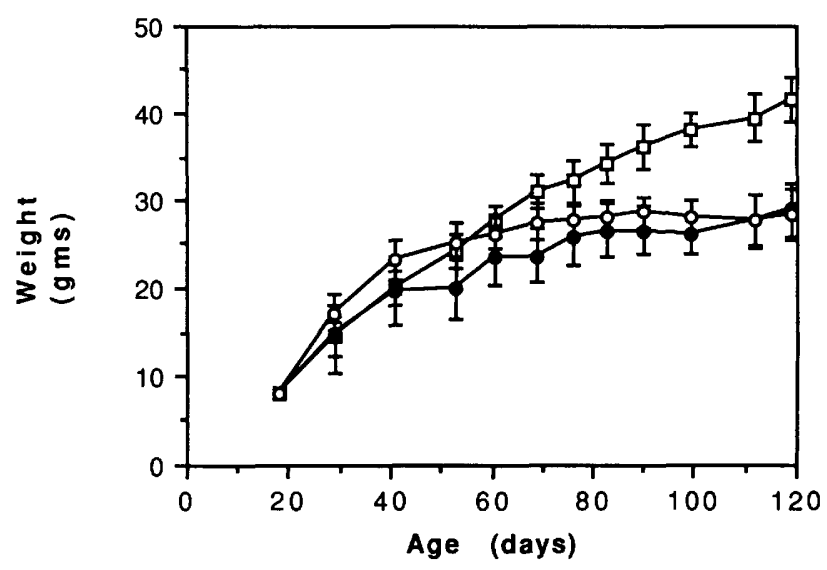

Figure 2. Growth curves of strain $1(O)$ and $8(O)$ MSG-treated mice. Weekly total body weights were measured for the transgenic mice and their nontransgenic littermates ( $\square$ ). The number of animals monitored in each group is 4 in strain 8 males; 5 in strain 1 males; 12 in the nontransgenic males. Similar differences were obtained for female transgenic and nontransgenic animals (data not shown). 

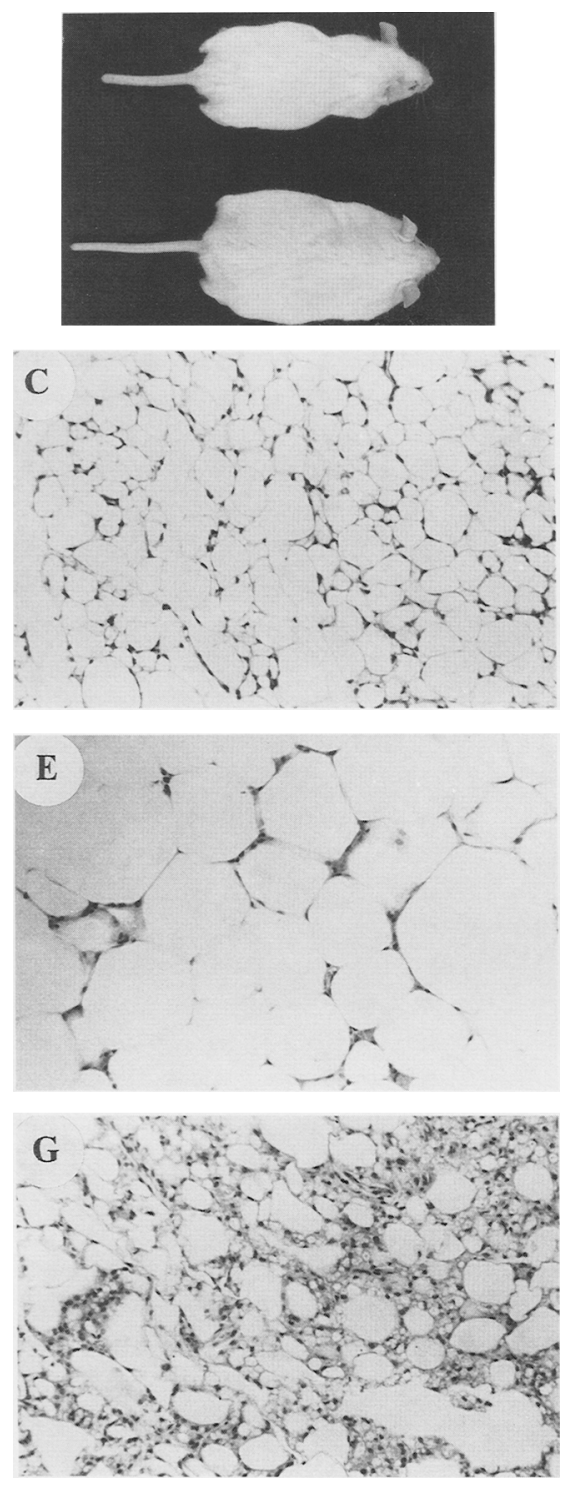
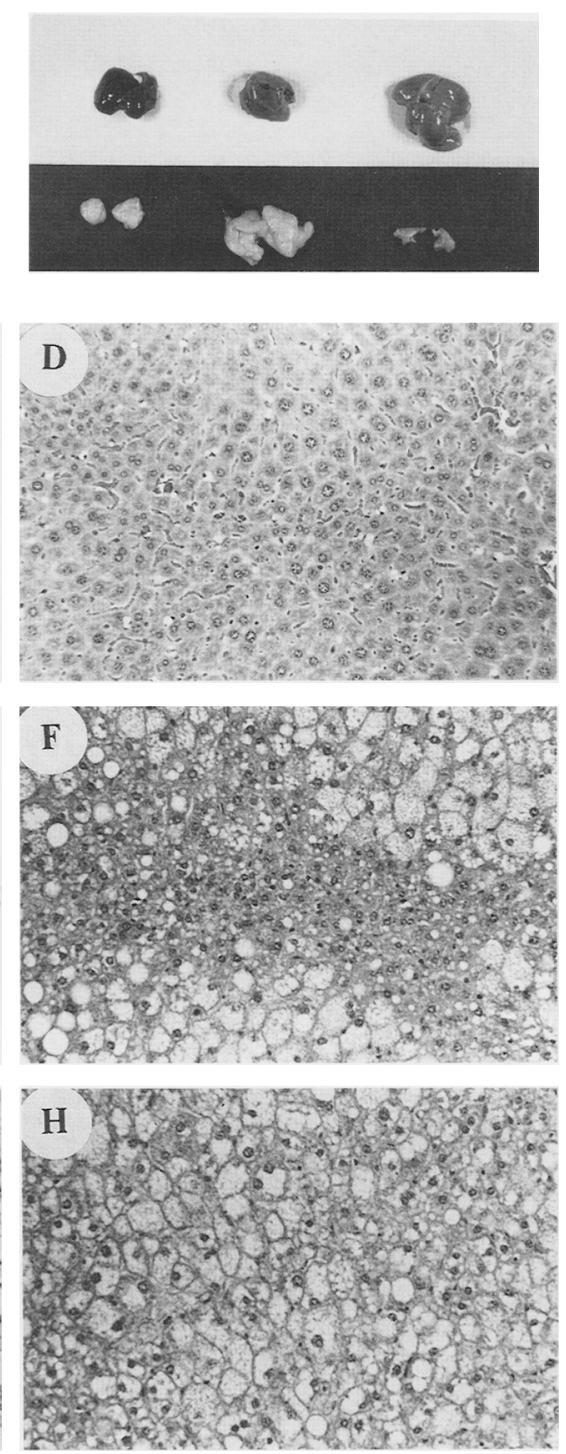

Figure 3. Morphology and pathology of the WAT and liver of the 5.4aP2-DT-A transgenic mice. $(A)$ MSG-treated nonobese strain 1 male (top) and an obese nontransgenic littermate (bottom). (B) Liver (top row) and epididymal WAT pad (bottom row) from (left to right) untreated strain 1 transgenic, MSG-treated obese nontransgenic, and MSG-treated nonobese strain 1 transgenic animals. $\{C \mid$ Hematoxylin and eosin-stained (H\&E) WAT from strain $1 .(D) \mathrm{H} \& \mathrm{E}$-stained liver from strain 1. (E) H\&E-stained WAT from MSGtreated, obese nontransgenic animal. $(F)$ H\&E-stained liver from MSG-treated, obese nontransgenic animal. $(G) \mathrm{H} \& \mathrm{E}-$ stained WAT from MSG-treated strain 1. (H) H\&E-stained liver from MSG-treated strain 1. Magnification, $236 \times$. treated with MSG were morbidly obese and weighed, on average, 10 grams more than their MSG-treated transgenic littermates (Fig. 2; Table 2). This was attributable primarily to excess WAT, as can be seen in Figure $3 \mathrm{~B}$ and Table 2; for example, the average epididymal fat pad weight of nontransgenic animals is almost $10 \times$ greater than the fat pads of the transgenic mice. In addition, body composition analysis of MSG-treated transgenic and nontransgenic mice showed that protein mass did not differ between the two groups and that the difference in weight was the result of lipid content (P. Wright and S.R. Ross, unpubl.).

Histopathological analysis of the WAT of non-MSGtreated strain 1 transgenic animals showed that this strain had relatively normal morphology, with unilocular lipid droplets characteristic of white adipocytes fa representative example is shown in Fig. $3 \mathrm{Cl}$. In contrast, the observable WAT from the MSG-treated transgenic mice (Fig. 3G) showed extensive hypertrophy and necrosis, characterized by monocytic infiltration; moreover, the WAT of these animals contained cells with the appearance of stroma and preadipocytes. As expected, MSG-treated obese nontransgenic mice had abundant WAT that had adipocytes with very large unilocular lipid droplets (Fig. 3E).

\section{MSG-treated aP2-DT-A transgenic mice develop hyperlipidemia and fatty liver}

The animals in which obesity was genetically blocked via expression of the toxin transgene represent an opportunity to analyze the relationship between obesity and some of its pathological correlates. Thus far, we have examined serum lipid levels and fatty changes in the liver (Table 3). MSG treatment induces a mild hypertriglyceridemia and hypercholesteremia that accompanies 
Table 3. Serum cholesterol and triglyceride levels are elevated in MSG-treated transgenic mice

\begin{tabular}{lccccc}
\hline Strain & $\begin{array}{l}\text { Age } \\
\text { (months) }\end{array}$ & MSG & $\begin{array}{l}\text { Cholesterol } \\
(\mathrm{mg} / \mathrm{dl})\end{array}$ & $\begin{array}{l}\text { Tri- } \\
\text { glycerides } \\
(\mathrm{mg} / \mathrm{dl})\end{array}$ & Number $^{\mathrm{a}}$ \\
\hline 1 & 4 & yes & $81 \pm 6$ & $182 \pm 16$ & $2(6)$ \\
& $5-8$ & & $256 \pm 27$ & $461 \pm 168$ & $5(7)$ \\
8 & 4 & yes & $120 \pm 5$ & $218 \pm 26$ & $2(7)$ \\
NT $^{\mathrm{b}}$ & 4 & yes & $90 \pm 30$ & $177 \pm 30$ & $3(9)$ \\
& $5-8$ & & $155 \pm 45$ & $208 \pm 56$ & $5(8)$ \\
1 & 3 & no & $58 \pm 20$ & $96 \pm 25$ & $2(7)$ \\
8 & 4 & no & $51 \pm 7$ & $57 \pm 21$ & $2(6)$ \\
NT $^{\text {b }}$ & $2-4$ & no & $72 \pm 25$ & $106 \pm 19$ & $5(13)$ \\
& $5-8$ & & $145 \pm 32$ & $86 \pm 15$ & $3(6)$ \\
\hline
\end{tabular}

Equal amounts of sera from two to four mice of each strain fasted for 6-12 hr were pooled, except for the older (5-7 month) mice, which are values for sera from one to two mice.

${ }^{a}$ The number of pooled sera averaged; the total number of animals analyzed is shown in parentheses.

b(NT) Nontransgenic.

the obesity. In transgenic strains treated with MSG, there was no reversal of the hyperlipidemia; the levels were actually higher in the MSG-treated, nonobese transgenic animals than in their MSG-treated obese nontransgenic counterparts. The hyperlipidemia was generally more severe in older mice (Table 3 ).

In contrast to the nontransgenic MSG-treated animals, which developed only moderate fatty liver (Fig. 3F), the MSG-treated transgenic mice also developed gross hepatomegaly as a result of severe fatty changes in the liver

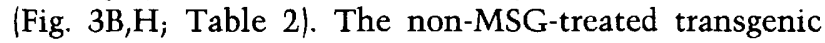
mice had normal liver morphology (Fig. 3D). No histopathological changes were seen in other major organs of the transgenic mice (data not shown).

\section{Reduction of adiposity via targeted expression of the DT-A transgene restores fertility in MSG-treated females}

MSG-treated females, but not males, are infertile /Olney 1969; S. Ross, unpubl.). This defect was thought to be related to the primary hypothalamic dysfunction, resulting in inappropriate endocrine control of ovulation. To determine whether the hypothalamic lesion created by MSG treatment did cause female infertility in the absence of obesity, three strain 1 , two strain 8 , and four nontransgenic MSG-treated females were left in mating with their male siblings for 1 month after puberty. Two strain 1 and one strain 8 transgenic females conceived and delivered live litters, whereas none of the nontransgenic MSG-treated female littermates conceived.

Both transgenic and nontransgenic MSG-treated animals had shortened body axes relative to untreated mice, indicating that the treatment resulted in hypothalamic damage. For example, the average nose-to-anus length of age-matched MSG-treated transgenic and nontransgenic animals was $9.5 \pm 0.15 \mathrm{~cm}\{n=12\}$ and $9.8 \pm 0.3 \mathrm{~cm}$ $(n=17)$, respectively, relative to the length of untreated transgenic or nontransgenic mice $(10.5 \pm 0.2[n=14)$, similar to the $10 \%$ decrease in body length reported previously (Olney 1969). Thus, reduction of adipose tissue mass in the context of the hypothalamic defect caused by MSG resulted in restoration of female fertility.

\section{Discussion}

We have used genetic manipulation to alter adipose depots by targeting expression of a toxin gene to this tissue. High-level expression resulted in newborn lethality accompanied by fatty fluid in the peritoneum, chylous ascites. This phenotype may result from a severe inability to metabolize the high levels of dietary lipid found in milk, presumably because of fat cell dysfunction. Although adipose tissue is not abundant in newborn rodents, our results indicate that this tissue may be important for neonatal development. However, further studies are needed to address this issue.

In contrast, low-level expression of the toxin gene in adipose tissue had very little effect on the WAT of mice not induced to become obese by MSG injection. Interestingly, in strain 8 , untreated young animals $K<4$ months) had amounts of fat similar to their nontransgenic littermates; however, older strain 8 transgenic animals ( $>6$ months) had much smaller adipose tissue depots (data not shown). Strain 1 mice had no apparent alteration in either WAT or BAT deposits at any age, consistent with the observation that the level of transgene expression in this latter strain is barely detectable (Fig. 1B).

Low-level expression of the attenuated toxin gene had a dramatic effect on the adipose tissue of the MSGtreated transgenic mice, resulting in a complete resistance to obesity. This effect in the MSG-treated transgenic mice could be the result of several phenomena. Increased proliferation of adipocytes occurs at an earlier age in the MSG-treated animals, which could lead to greater effects of the toxin. Moreover, there are a variety of metabolic alterations in adipocytes during the progression from the lean to obese state in rodents, resulting in an increased basal turnover in lipid synthesis and mobilization (Crandall and DiGirolamo 1990); this progression could cause an increase in the expression of the transgene, which is under the transcriptional control of the regulatory region of the aP2 lipid-binding protein gene. Consistent with this is the observation that there is a loss of adipose tissue in aged non-MSG-treated strain 8 mice; accumulation of WAT in nonobese mice is an age-dependent process, and the increased proliferative capacity of these cells in older mice (Ailhaud et al. 1992) could result in concomitant age-dependent effects on fat cell function by the transgene.

Using these transgenic mice, we have begun to evaluate the links between obesity and the medical problems that accompany this common disorder. Obese individuals often have elevated serum lipid levels, and hyperlipidemia is an important risk factor for cardiovascular disease and other medical problems. The MSG-treated 
transgenic mice described here are resistant to obesity and yet their serum levels of triglycerides and cholesterol are elevated relative to their nonobese siblings. At older ages, these levels are even greater than that seen in their obese, nontransgenic counterparts. Thus, in this model, it is clear that the hyperlipidemia that accompanies chemically induced obesity is not a secondary consequence of the increased adipose mass.

One possible explanation for the increase in serum lipids that ordinarily occurs in obesity is that there is an increase in lipid ingestion. This is unlikely to occur in the DT-A transgenic mice because the MSG-treated rodent is not hyperphagic (Olney 1969); and even after total denial of access to food, they retain significant amounts of body fat (Cameron et al. 1978). Thus, our results suggest that obesity, at least in this model, could be a result rather than a cause of the elevated lipids in the blood. In the MSG-treated obese rodent, excessive adipose mass may be a response, at least in part, to elevated lipids in the blood that occur because of metabolic dysfunction related to MSG treatment. Undoubtedly, the more severe hepatomegaly in MSG-treated transgenic mice is secondary to the greater hyperlipidemia that occurs because these animals are unable to expand their adipose mass.

Another clinical disorder associated with obesity is infertility. In both the genetic and MSG models of obesity, infertility is the result of inappropriate reproductive endocrine signaling, perhaps stemming from hypothalamic defects. We have shown that reduction of adipose tissue mass alone is capable of restoring fertility to females treated with MSG. These results imply that the infertility in obese animals could result from altered adipose tissue metabolism itself [i.e., high estrogen or androgen levels because of steroid production in fat cells, as has been hypothesized for obese human females (Foster 1985)].

We have shown the feasibility of creating mouse strains that are genetically resistant to obesity. In addition to the analyses shown here, it will now be possible to use these and similar transgenic mice to explore the relationship between obesity and other important clinical correlates, such as hypertension, atherosclerosis, and diabetes.

\section{Materials and methods \\ Transgene construction}

The aP2-DT-A transgene was constructed as follows: A 680-bp fragment containing the tox-176 attenuated DT-A gene, kindly provided by I. H. Maxwell (University of Colorado, Boulder), was ligated to a fragment containing the SV40 small $t$ splice and polyadenylation site, and this insert was put into the plasmid $5.4 \mathrm{aP} 2 / \mathrm{SK}+$ (Ross et al. 1992). The insert DNA used for injection was liberated from this plasmid as an EcoRI-NotI fragment and purified as described (Ross et al. 1990).

\section{Transgenic mice}

Female and male Swiss Webster colonies of germ-free-derived, defined-flora animals were purchased from the National Cancer
Institute, Frederick Cancer Research Facility (Frederick, MD). Transgenic mice were produced and identified by PCR and Southern blot analysis (Ross et al. 1992).

\section{MSG treatment}

Transgenic animals heterozygous for the transgene were mated with nontransgenic mice of the opposite sex. MSG dissolved in saline solution was injected subcutaneously $(2 \mathrm{mg} / \mathrm{gm}$ body weight) from day 1 to day 7 after birth into the entire litter. At $\sim 3$ weeks of age, the animals were analyzed, as described above, for the presence of the transgene; the nontransgenic, MSGtreated littermates served as controls for the experiments. All mice were weighed on a weekly basis, starting at $\sim 3$ weeks of age.

\section{RNA analysis}

RNA was extracted by guanidine thiocyanate extraction and $\mathrm{CsCl}$ gradient centrifugation (Chirgwin et al. 1979). Northern blots (Lehrach et al. 1977) were carried out with the following probes: DT-A, mouse aP2 (Spiegelman et al. 1983), $\beta$-actin, or rat UCP (Bouillaud et al. 1986; a gift from D. Ricquier, CNRS, France). RNase $T_{1}$ protection assays were performed using a probe that detects the $3^{\prime}$ SV40 polyadenylation signals present in the diphtheria toxin transgene, as described previously (Ross et al. 1992). All RNA samples were tested for integrity by Northern blot analysis and hybridization to a $\beta$-actin probe.

\section{Serum cholesterol and triglyceride measurements}

All animals were housed on a constant light/dark cycle $/ 14 \mathrm{hr}$ light, $10 \mathrm{hr}$ dark) and were fed ad libitum Agway Prolab RMH 4020 Rodent Chow, containing $5 \%$ crude fat. Sera were obtained by retro-orbital bleeding of ether-anesthetized mice. Measurements of cholesterol and triglyceride levels were carried out by the Biologic Resources Laboratory of the University of Illinois and were determined by enzymatic reaction followed by spectrophotometric quantitation, using Express kits and a Ciba/Corning Express 550 spectrophotometer. Mice were combined across groups NT, 1 , and $8(-$ MSG), and NT, 1 , and 8 $(+\mathrm{MSG})$, and an analysis of variants was conducted to test for differences between the + and - groups. The differences for both triglycerides and cholesterol were highly significant. The cholesterol comparison yielded an $\mathrm{F}$ test of $7.768(\mathrm{P}<0.009)$; likewise, the triglyceride comparison gave an F test of 12.591 (P $<0.001$ ).

\section{Acknowledgments}

We thank P. Wright for expert technical assistance, N. Fox and E. Emeson for advice and helpful discussions on histopathology, and D. Massey for help with the statistical analyses. This work was supported by a U.S. Public Health Service grant (DK 31405 to B.M.S.) and the March of Dimes (S.R.R.)

The publication costs of this article were defrayed in part by payment of page charges. This article must therefore be hereby marked "advertisement" in accordance with 18 USC section 1734 solely to indicate this fact.

\section{References}

Ailhaud, G., P. Grimaldi, and R. Negrel. 1992. Cellular and molecular aspects of adipose tissue development. Annu. Rev. Nutr. 12: 207-233. 
Behringer, R.R., L.S. Mathews, R.D. Palmiter, and R.L. Brinster. 1988. Dwarf mice produced by genetic ablation of growth hormone-expressing cells. Genes \& Dev. 2: 453-461.

Bernstein, A. and M. Breitman. 1989. Genetic ablation in transgenic mice. Mol. Biol. Med. 6: 523-540.

Bouillaud, F., J. Weissenbach, and D. Ricquier. 1986. Complete cDNA-derived amino acid sequence of rat brown fat uncoupling protein. I. Biol. Chem. 261: 1487-1490.

Bray, G.A. and D.A. York. 1979. Hypothalamic and genetic obesity in experimental animals: An autonomic and endocrine hypothesis. Physiol. Rev. 59: 719-809.

Breitman, M.L., H. Rombola, I.H. Maxwell, G.K. Klintworth, and A. Bernstein. 1990. Genetic ablation in transgenic mice with an attenuated diptheria toxin A gene. Mol. Cell. Biol. 10: $474-479$.

Cameron, D.P., L. Cutbush, and F. Opat. 1978. Effects of monosodium glutamate-induced obesity in mice on carbohydrate metabolism in insulin secretion. Clin. Exp. Pharmacol. Physiol. 5: 41-51.

Chirgwin, J.M., A.E. Prxybyla, R.J. MacDonald, and W.J. Rutter. 1979. Isolation of biologically active ribonucleic acid from sources enriched in ribonuclease. Biochemistry 18: 52945299.

Coleman, D.L. 1982. Diabetes-obesity syndromes in mice. Diabetes 31: 1-6.

Crandall, D.L. and M. DiGirolamo. 1990. Hemodynamic and metabolic correlates in adipose tissue: Pathyphysiologic considerations. FASEB J. 4: 141-147.

Evans, G.A. 1989. Dissecting mouse development with toxigenics. Genes \& Dev. 3: 259-263.

Foster, D.W. 1985. Eating disorders: Obesity and anorexia nervosa. In Textbook of endocrinology (ed. J.D. Wilson and D.W. Foster), pp. 1081-1107. W.B. Saunders, Philadelphia, PA.

Friedman, J.M. and R.L. Leibel. 1992. Tackling a weighty problem. Cell 69: 217-220.

Graves, R.A., P. Tontonoz, S.R. Ross, and B.M. Spiegelman. 1991. Identification of a potent adipocyte-specific enhancer: Involvement of an NF-1-like factor. Genes \& Dev. 5: 428437.

Herbertson, B.M. and M.E. Wallace. 1964. Chylous ascites in newborn mice. J. Med. Genet. 1: 10-23.

Kendall, S.K., T.L. Saunders, L. Jin, R.V. Lloyd, L.M. Glode, T.M. Nett, R.A. Keri, J.H. Nilson, and S.A. Camper. 1991. Targeted ablation of pituitary gonadotropes in transgenic mice. Mol. Endocrinol. 5: 2025-2036.

Lehrach, H., D. Diamond, J.M. Wozney, and H. Boedtker. 1977. RNA molecular weight determinations by gel electrophoresis under denaturing conditions, a critical re-examination. Biochemistry 16: 4743-4751.

Leiter, E.H., W.G. Beamer, L.D. Shultz, J.E. Barker, and P.W. Lane. 1987. Mouse models of genetic diseases. In Medical and experimental mammalian genetics: $A$ perspective (ed. V.A. McKusick et al.), pp. 221-257. Alan R. Liss, New York.

Maxwell, F., I.H. Maxwell, and L.M. Glode. 1987. Cloning, sequence determination, and expression in transfected cells of the coding sequence for the tox 176 attenuated diptheria toxin A chain. Mol. Cell. Biol. 7: 1576-1579.

Olney, J.W. 1969. Brain lesions, obesity and other disturbances in mice treated with monosodium glutamate. Science 164: 719-721.

Palmiter, R.D., R.R. Behringer, C.J. Quaife, F. Maxwell, I.H. Maxwell, and R.L. Brinster. 1987. Cell lineage ablation in transgenic mice by cell-specific expression of a toxin gene. Cell 50: 435-443.

Pizzi, W.J. and J.E. Barnhart. 1976. Effects of monosodium glu- tamate on somatic development, obesity and activity in the mouse. Pharmacol. Biochem. Behav. 5: 551-557.

Ross, S.R., R.A. Graves, A. Greenstein, K.A. Platt, H.-L. Shyu, B. Mellovitz, and B.M. Spiegelman. 1990. A fat-specific enhancer is the primary determinant of gene expression for adipocyte P2 in vivo. Proc. Natl. Acad. Sci. 87: 9590-9594.

Ross, S.R., L. Choy, R.A. Graves, N. Fox, V. Solevjeva, S. Klaus, D. Ricquier, and B.M. Spiegelman. 1992. Hibernoma formation in transgenic mice and isolation of a brown adipocyte cell line expressing the uncoupling protein gene. Proc. Natl. Acad. Sci. 89: 7561-7565.

Spiegelman, B.M., M. Frank, and H. Green. 1983. Molecular cloning of mRNA from $3 \mathrm{~T} 3$ adipocytes. $/$. Biol. Chem. 258: 10083-10089.

Wallace, M.E. 1979. Analysis of genetic control of chylous ascites in ragged mice. Heredity 43: 9-18. 


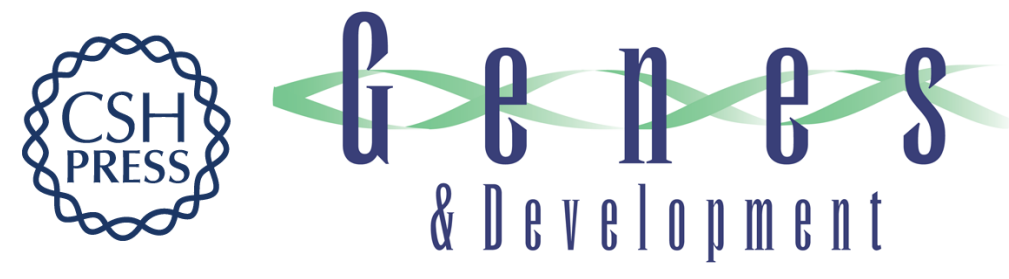

\section{Targeted expression of a toxin gene to adipose tissue: transgenic mice resistant to obesity.}

S R Ross, R A Graves and B M Spiegelman

Genes Dev. 1993, 7:

Access the most recent version at doi:10.1101/gad.7.7b.1318

References This article cites 24 articles, 12 of which can be accessed free at:

http://genesdev.cshlp.org/content/7/7b/1318.full.html\#ref-list-1

License

Email Alerting

Receive free email alerts when new articles cite this article - sign up in the box at the

Service top right corner of the article or click here.

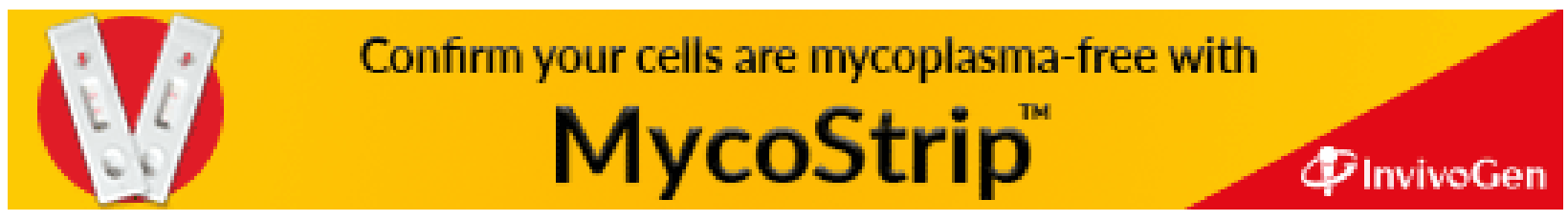

